This document is the accepted manuscript version of the following article:

ChemComm Mairena, A., Mendieta, J. I., Stetsovych, O., Terfort, A., Stará, I. G., Starý, I., Ernst, K. H. (2019). Heterochiral recognition among functionalized heptahelicenes on noble metal surfaces. Chemical Communications, 55(71), 10595-10598. https://doi.org/10.1039/C9cC05317D

\title{
Heterochiral recognition among functionalized heptahelicenes on noble metal surfacest
}

Received 00th January 20xx, Accepted 00th January 20xx

DOI: $10.1039 / \times 0 \times x 00000 x$

www.rsc.org/
Anaïs Mairena ${ }^{a}$, Jesus I. Mendieta ${ }^{b}$, Oleksandr Stetsovych ${ }^{b}$, Andreas Terfort ${ }^{c}$, Irena G. Starád, Ivo Starýd ${ }^{\text {, Pavel Jelínek }}{ }^{\mathrm{b}}$, and Karl-Heinz Ernst*a,b,e
Chiral recognition among three differently functionalized heptahelicene derivatives on $\mathrm{Ag}(\mathbf{1 1 1})$ and $\mathrm{Au}(\mathbf{1 1 1})$ surfaces has been studied with scanning tunnelling microscopy. All three species were found to self-assemble into racemic zigzag structures, with alternation of $(M)$ - and $(P)$-enantiomers.

The problem of conglomerate versus racemate crystallization is of paramount importance for chiral technologies. ${ }^{1}$ Although more than 170 years have passed since Pasteur's seminal discovery of conglomerate crystallization of sodium ammonium tartrate, ${ }^{2}$ this phenomenon is still not understood at all. ${ }^{3}$ Early empirical explanations based on crystal densities were shown to have limited general applicability. ${ }^{4-7}$ Understanding the complex problem of molecular recognition in crystallization calls for well-defined model systems as, for example, the aggregation of chiral molecules on metal surfaces in ultrahigh vacuum. ${ }^{8,9}$ Besides the excellent control of experimental conditions, this approach benefits in particular from the submolecular resolution provided by scanning tunnelling microscopy (STM). ${ }^{10}$

Beyond chiral recognition, the surface self-assembly of helical aromatic hydrocarbons, so-called helicenes, is motivated by studying novel physical effects, such as chiroptical responses, electron spin selectivity or molecular electro-mechanics. ${ }^{11-14}$ Consequently, synthesis and functionalization of surfaces with helicenes has received increasing attention recently. ${ }^{15-17}$ There have been several reports on the fate of chiral crystallization of helicenes on various surfaces. The adsorption of heptahelicene $([7] \mathrm{H})$ on the three (111) surfaces of $\mathrm{Cu}, \mathrm{Ag}$ and

\footnotetext{
a. Empa, Swiss Federal Laboratories for Materials Science and Technology, 8600 Dübendorf, Switzerland E-mail: karl-heinz.ernst@empa.ch

b. Institute of Physics of the Czech Academy of Sciences, Cukrovarnická 10, 18221 Prague 6, Czech Republic E-mail: ernst@fzu.cz

Institut für Anorganische und Analytische Chemie, Goethe-Universität Frankfurt, Max-von-Laue-Straße 7, 60438 Frankfurt, Germany

d. Institute of Organic Chemistry and Biochemistry, Czech Academy of Sciences, Flemingovo náměstí 2, 16610 Prague 6, Czech Republic

e. Department of Chemistry, University of Zurich, 8057 Zurich, Switzerland

+ Electronic Supplementary Information (ESI) available: Details of - and additional
} molecular mechanics calculations. See DOI: 10.1039/x0xx00000xd

Au basically showed identical assembly motifs for racemate as well as the pure enantiomers. ${ }^{18}$ The racemate formed in all three cases zigzag rows with alternating $(M) /(P)$ enantiomers in a row. On $\mathrm{Cu}(100)$, however, [7] $\mathrm{H}$ crystallized into a twodimensional (2D) conglomerate phase consisting of homochiral domains built up from homochiral quadruplets. ${ }^{19}$ Homochiral quadruplets were also observed for 5-amino[6]helicene on the same surface, ${ }^{20}$ and alloying the $\mathrm{Cu}(100)$ surface with $\mathrm{Sn}$ caused racemate formation. ${ }^{21}$ At small coverages homochiral quadruplets of [7] $\mathrm{H}$ were also observed on $\mathrm{Ag}(100)$, but with increasing coverage the racemic zigzag row motif dominated again the self-assembly. ${ }^{22}$ Cyano-functionalized [7] $\mathrm{H}$, on the other hand, led to conglomerate formation on $\mathrm{Cu}(111) .^{23}$ Pentahelicene $([5] \mathrm{H})$ was found to form homochiral van der Waals dimers (vdW-dimers) on $\mathrm{Cu}(111)$, which, in turn, formed a racemate structure as long as second layer nucleation was avoided. ${ }^{24}$ Dibenzo[5] H in turn aggregated into a conglomerate on $\mathrm{Au}(111) .{ }^{25}$ Finally, 9,9'-bis[7] H was found to form a racemate phase on $\mathrm{Cu}(111),{ }^{26}$ while on-surface synthesized tris[4] $\mathrm{H}$ formed large homochiral domains. ${ }^{27}$ These examples show, that besides substrate surface periodicity and symmetry the functionalization of helicenes may play an important role for the fate of homo- or heterochiral recognition.
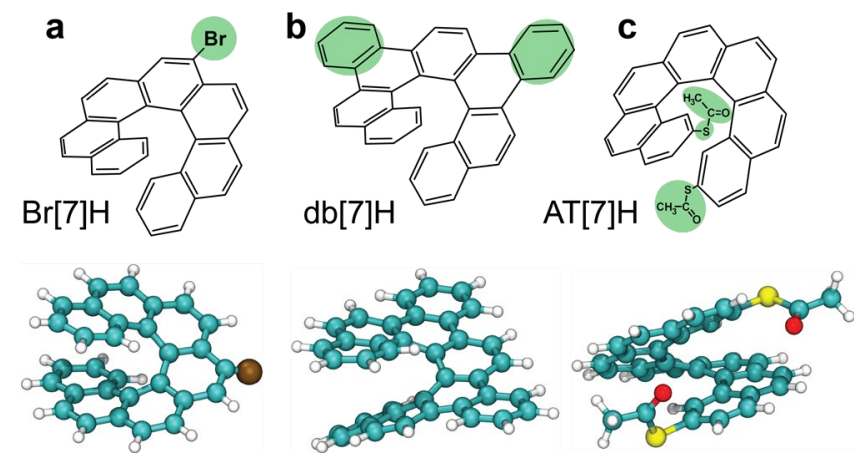

Figure 1. Molecular structure models of three heptahelicene derivatives. (a) 9-bromo$(\mathrm{Br}[7] \mathrm{H})$; (b) dibenzo- $(\mathrm{db}[7] \mathrm{H})$; and (c) S,S'-1,17-diacetothio- $(\mathrm{AT}[7] \mathrm{H})$ heptahelicene Only $(P)$-enantiomers are shown. The functional groups (bromo-, benzo- and Sacetylthiolate) are highlighted in green. 

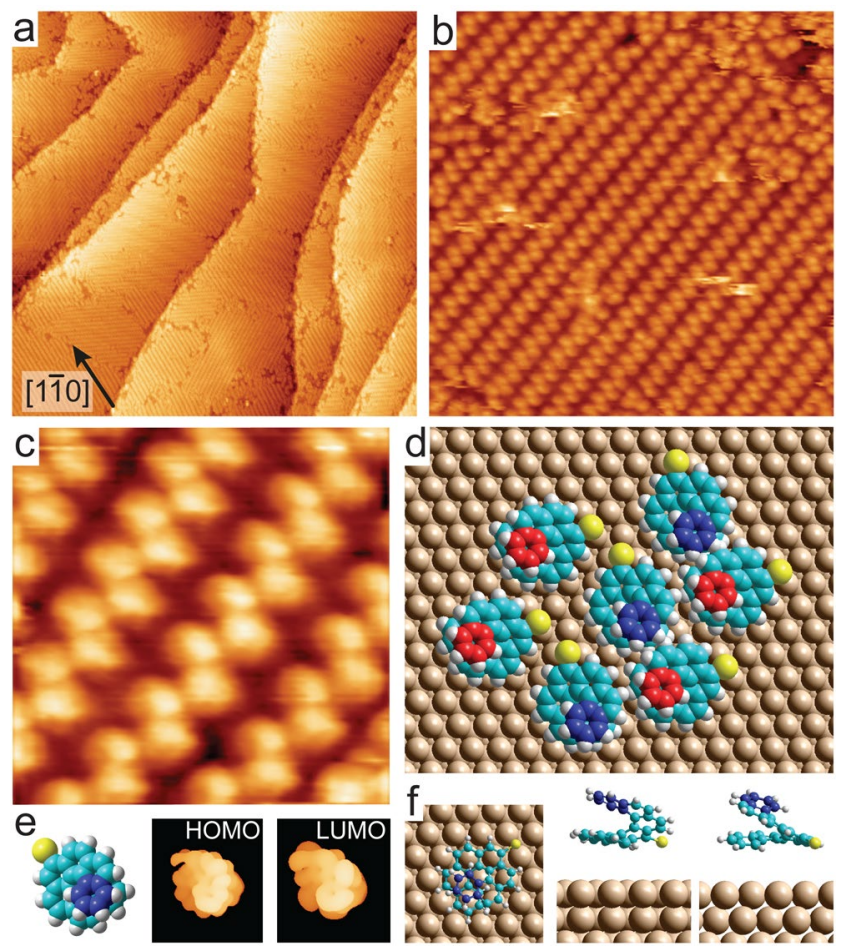

Figure 2. (a) Large scale STM image $(219 \mathrm{~nm} \times 219 \mathrm{~nm}, 28 \mathrm{pA},-2.8 \mathrm{~V})$ of a single layer of $\mathrm{Br}$ [7] $\mathrm{H}$ on $\mathrm{Au}(111)$. Within the ordered rotational domains molecules form lines oriented along the high-symmetry axes of the substrate. The [1] 0 ] direction of the Au substrate is indicated by the black arrow. (b) STM image $(26 \mathrm{~nm} \times 26 \mathrm{~nm}, 23 \mathrm{pA},-2.8 \mathrm{~V})$ of a domain showing zigzag row alignment. (c) STM image $(9.3 \mathrm{~nm} \times 9.3 \mathrm{~nm}, 23 \mathrm{pA},-2.8 \mathrm{~V})$ of the zigzag rows formed by $\mathrm{Br}[7] \mathrm{H}$ on $\mathrm{Au}(111)$. (d) Molecular model of the zigzag alignment based on STM images and AMBER force field calculations. The upper terminal ring of each molecule is highlighted in dark blue or red for $(M)$ - or $(P)$-enantiomers, respectively. (e) EHT electron density of the LUMO (right) and HOMO (middle) according to the orientation of the filled-space ball model of $(M)-B r[7] H$ (left). (f) Top and side views of the result of $A M B E R$ force field calculations for the single $(\mathrm{M})-\mathrm{Br}[7] \mathrm{H}$ on a four-layer $\mathrm{Au}(111)$ slab.

Here, we present a study of the molecular recognition of three different heptahelicene derivatives, namely, 9-bromoheptahelicene $\left(\mathrm{C}_{30} \mathrm{H}_{17} \mathrm{Br} ; \mathrm{Br}[7] \mathrm{H}\right)$, dibenzoheptahelicene (dinaphto$\left[2,1 ; 1^{\prime}, 2^{\prime}\right.$-f,j]picene, $\left.\mathrm{C}_{38} \mathrm{H}_{22}, \mathrm{db}[7] \mathrm{H}\right)$, and $\mathrm{S}, \mathrm{S}^{\prime}$-diacetylheptahelicene-2,17-dithiolate $\left(\mathrm{C}_{30} \mathrm{H}_{16} \mathrm{O}\left(\mathrm{SCOCH}_{3}\right)_{2} ; \mathrm{AT}[7] \mathrm{H}\right.$; Figure 1) on $\mathrm{Ag}(111)$ and $\mathrm{Au}(111)$. Although differently functionalized, all three [7] H species, when adsorbed as racemic mixture, selfassemble into heterochiral M/P-zigzag rows.

Chemical synthesis of the helicene derivatives has been described previously. ${ }^{14,26,28}$ Samples were prepared in ultrahigh vacuum by Ar ion sputtering of the metal surface, annealing and deposition by thermal sublimation of the [7] $\mathrm{H}$ derivatives at 443 $\mathrm{K}(\mathrm{Br}[7] \mathrm{H}), 570 \mathrm{~K}(\mathrm{db}[7] \mathrm{H})$ and $450 \mathrm{~K}(\mathrm{AT}[7] \mathrm{H})$, onto $\mathrm{Au}(111)$ and $\mathrm{Ag}(111)$ surfaces held at room temperature or at $350 \mathrm{~K}$. Molecular ordering was not effected by deposition in this temperature range. Different coverages were adjusted by different exposure times. The molecular layers were analysed in-vacuo by STM at different temperatures and compared to molecular models based on classical force field calculations (ESIt).

The outcome of self-assembly of $\mathrm{Br}$ [7] H was studied at $60 \mathrm{~K}$. For the close-packed monolayer $(\mathrm{ML})$ the molecules form ordered domains built up by zigzag rows (Figure 2) $\ddagger$. The arrangement of the enantiomers into zigzag rows is similar to the one determined for [7] $\mathrm{H}$ on $\mathrm{Au}(111), \mathrm{Ag}(111)$ and $\mathrm{Cu}(111), 18,29$ including the fact that the rows are oriented parallel to the highsymmetry directions in case of $\mathrm{Ag}(111)$ and $\mathrm{Au}(111) .{ }^{18}$ The [7] $\mathrm{H}$ zigzag row was identified as heterochiral composition with alternating $(M)$ - and $(P)$-enantiomers and was not observed for the pure enantiomers. ${ }^{30}$ Note that $\mathrm{Br}$ is still attached to the helical backbone at room temperature on $\mathrm{Au}(111) .{ }^{31}$ Hence, replacement of the $\mathrm{H}$ atom at carbon $\# 9$ by a $\mathrm{Br}$ atom does not change the preference for heterochiral recognition. The most favourable configuration of a single $\mathrm{Br}[7] \mathrm{H}$ molecule was calculated from 216 different initial configurations with AMBER force field (Figure 2). Each molecule adsorbs with the $\mathrm{Br}$ atom located above a bridge site between two Au surface atoms. A model of the self-assembled $\mathrm{Br}$ [7] $\mathrm{H}$ structure, which is based on STM images and Extended Hückel theory (EHT) frontier orbital modelling of $\mathrm{Br}[7] \mathrm{H}$ is presented in Fig. 1d. It is known from crystal structure studies that $\mathrm{Br} \cdots \mathrm{Br}$ interactions are not very dominant, ${ }^{32,33}$ and on the gold surface here the additional $\mathrm{Br}$ atoms do not cause a different self-assembly motif than observed for [7] $\mathrm{H}$. Forcefield modelling yields as binding energy of $\mathrm{Br}$ [7] H enantiomers in a vdW-dimer of $4.5 \mathrm{kcal} / \mathrm{mol}$ (Fig. S1, $\mathrm{ESI}+$ ), which is larger than the $3.0 \mathrm{kcal} / \mathrm{mol}$ calculated for [7] $\mathrm{H}$ on $\mathrm{Cu}(111)$. The distance between two $\mathrm{Br}$ [7] $\mathrm{H}$ is also larger than observed between two [7] H. Consequently, the occupied surface area per molecule is $1.45 \mathrm{~nm}^{2}$, which is higher than the $1.04 \mathrm{~nm}^{2} /$ molecule found for [7] $\mathrm{H} .{ }^{18,29}$ This observation might also explain the better long range order observed here for $\mathrm{Br}$ [7] H than for [7] H on $\mathrm{Au}(111)$ due to better match between adsorbate and Au substrate lattice.

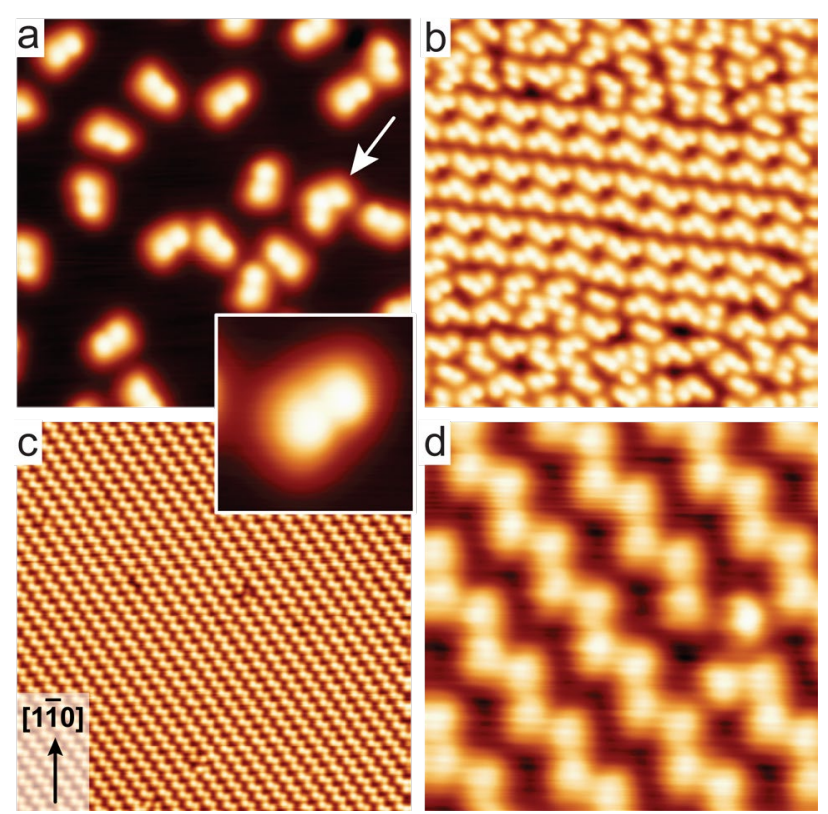

Figure 3. STM images of racemic db[7] $\mathrm{H}$ on $\mathrm{Ag}(111)$. (a) The STM image $(20 \mathrm{~nm} \times 20 \mathrm{~nm}$, $0.5 \mathrm{~V}, 20 \mathrm{pA}$ ) at low coverages shows vdW-dimers and a heterochiral triplet (arrow). Inset: $4 \mathrm{~nm} \times 4 \mathrm{~nm}$ STM image of a vdW-dimer. (b) The STM image ( $25 \mathrm{~nm} \times 25 \mathrm{~nm}, 0.5$ $\mathrm{V}, 10 \mathrm{pA}$ ) at $0.8 \mathrm{ML}$ shows self-assembly of heterochiral triplets. (c) STM image $(50 \mathrm{~nm} \times$ $50 \mathrm{~nm}, 350 \mathrm{mV}, 10 \mathrm{pA}$ ) of a single domain at a full monolayer coverage. (d) STM image $(8 \mathrm{~nm} \times 8 \mathrm{~nm}, 350 \mathrm{mV}, 10 \mathrm{pA})$ of the zigzag rows. The substrate orientation indicated in (c) applies to all images. 


\section{ChemComm}

\section{COMMUNICATION}

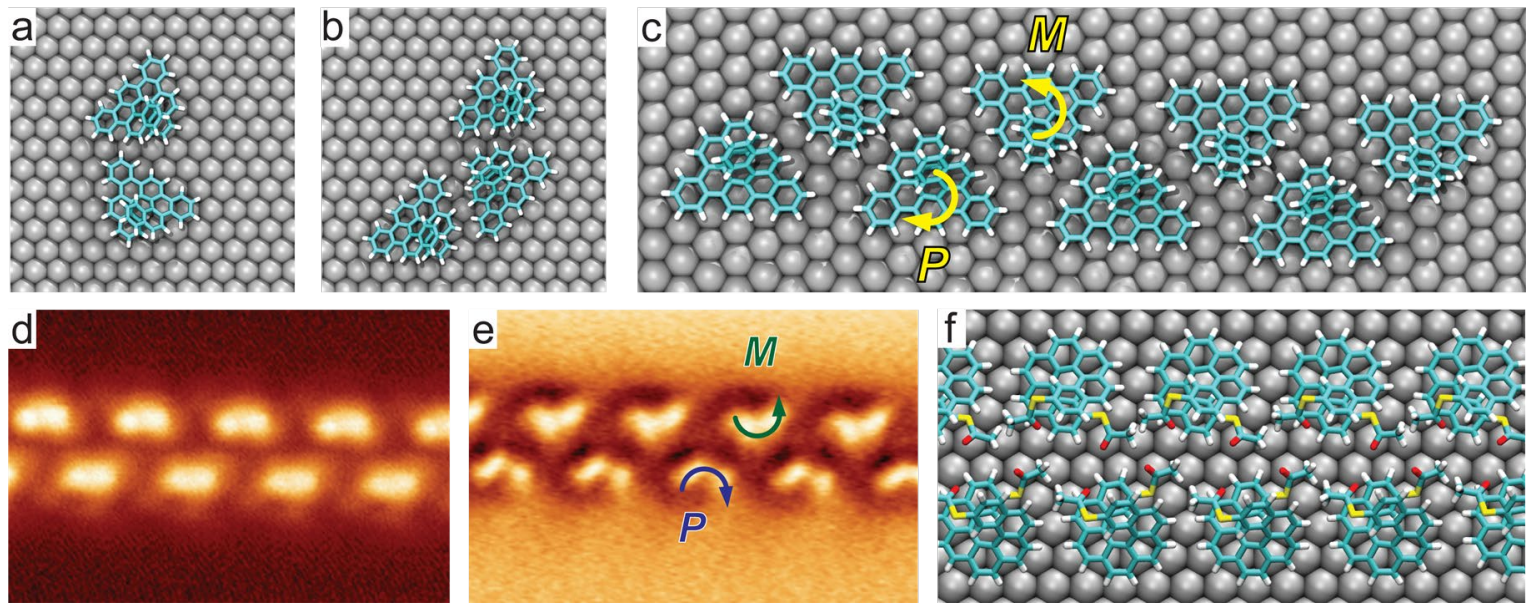

Figure 4. Relaxed structures for $\mathrm{db}[7] \mathrm{H}$ and $\mathrm{AT}[7] \mathrm{H}$ on $\mathrm{Ag}(111)$ based on force field mediated molecular dynamics. (a) Heterochiral db[7] $\mathrm{H}$ vdW-dimer. (b) Heterochiral db[7] H triplet. (c) Heterochiral db[7]H zigzag chain. (d,e) STM and NC-AFM images $\left(4.5 \mathrm{~nm} \times 3 \mathrm{~nm}, \mathrm{U}=30 \mathrm{mV}, \mathrm{A}_{\text {osc: }}: 40 \mathrm{pm} ; \mathrm{I}_{\max }: 2.8 \mathrm{pA}, \mathrm{I}_{\text {min }}: 0 \mathrm{pA}, \mathrm{df}_{\max }: 405.77 \mathrm{mHz}\right.$, df max $\left.:-235.35 \mathrm{mHz}\right)$ of an AT[7]H zigzag chain. The upper row consists of (M)-AT[7]H, the lower of (P)-AT[7] H. This assignment is based on the different frequency shift contrast of the two lobes of the molecules. (f) Segment of a relaxed heterochiral AT[7]H zigzag chain as obtained for 12 molecules.

The result of 2D self-assembly of racemic $\mathrm{db}$ [7] $\mathrm{H}$ was studied on the $\mathrm{Ag}(111)$ surface. Figure 3 shows STM images acquired at 1.2 $\mathrm{K}$. Already at very low coverages the formation of vdW-dimers is observed. Because no vdW-dimers but rather triplets are formed by the pure enantiomers under same conditions, ${ }^{28}$ it must be assumed that these vdW-dimers consist of both enantiomers. A similar observation has been made previously for [7] $\mathrm{H}$ on $\mathrm{Cu}(111) .{ }^{34}$ At intermediate coverage of $\mathrm{dB}[7] \mathrm{H}$ on $\mathrm{Ag}(111)$ assembly into triplets occurs (Figure $3 \mathrm{~b})$. The triplets are different with respect to the triangular, $C_{3}$-symmetric homochiral triplets and must be considered as heterochiral precursors of the zigzag rows observed at monolayer saturation (Figure $3 \mathrm{c}, \mathrm{d}$ ). As observed for [7] $\mathrm{H}$ on $\mathrm{Ag}(111),{ }^{18}$ the zigzag rows run parallel to highly symmetric directions of the $\mathrm{Ag}(111)$ surface.

Structural models based on classical forcefield modelling are presented for the experimentally observed $\mathrm{db}[7] \mathrm{H} v \mathrm{vW}$-dimer, triplet and zigzag row motifs (Figure 4). The same models displayed with vdW radii are presented in the ESIt (Fig. S2). The binding energy for the vdW-dimer amounts to $2.21 \mathrm{kcal} / \mathrm{mol}$, while the best homo vdW-dimer has only $0.72 \mathrm{kcal} / \mathrm{mol}$. The shown heterochiral triplet is also favoured over the best homochiral arrangement (Fig. S3, ESIt).

For AT[7]H with its acetylthiolate group intermolecular interaction via hydrogen bonds might be expected. However, STM images acquired at $1.2 \mathrm{~K}$ show again the zigzag motif (Fig. 4d, Fig. S4). In order to discriminate between enantiomers, the achieved STM contrast was hardly sufficient. Non-contact atomic force microscopy (nc-AFM) with a carbon monoxidemodified tip, however, reveals opposite handedness in a single zigzag chain (Fig. 4e). Force field modelling relaxation of 12 randomly positioned molecules delivers indeed a heterochiral zigzag chain (Fig. S5), of which a segment is shown in Figure 4f. The modelling also suggests, as for $\mathrm{Br}[7] \mathrm{H}$ and $\mathrm{db}[7] \mathrm{H}$, identical surface binding sites (Fig. 4d).

Previously performed density functional theory (DFT) calculations for $\mathrm{AT}[7] \mathrm{H}$ on $\mathrm{Ag}(111)$ showed that a sulphur atom gets pinned to a single $\mathrm{Ag}$ surface atom. ${ }^{14}$ The proximal phenanthrene groups, however, show a similar distance (3 $\AA$ ) to the surface as plain [7] $\mathrm{H}$ on various surfaces, ${ }^{12}$ suggesting an additional surface binding through that group. DFT calculations for [5] $\mathrm{H}$ on $\mathrm{Cu}(111)^{24}$ and $\mathrm{db}[7] \mathrm{H}$ on $\mathrm{Ag}(111)^{28}$ showed that the C6 rings of the proximal phenanthrene group tend to be placed above threefold hollow sites. The same conclusion has been made for pentacene on $\mathrm{Cu}(111) \cdot{ }^{35,36} \mathrm{~A}$ favoured binding mode with the metal surface limits therefore to some extent the modes of intermolecular interactions. Apparently, this limitation favours then the heterochiral alignment over the homochiral one for the (111) surfaces of gold and silver. It would be interesting to study the fate of $2 \mathrm{D}$ crystallisation of these three helicene species on the (100) surfaces of $\mathrm{Ag}$ and $\mathrm{Cu}$, where [7] $\mathrm{H}$ at low coverage showed homochiral recognition. Financial support from the Schweizerischer Nationalfonds (grant 200020-163296) is gratefully acknowledged. This work was in part financially supported by Czech Science Foundation grants (17-24210Y, 16-08327S, 15-19672S and 14-374527G), the Institute of Organic Chemistry and Biochemistry, Czech Academy of Sciences (RVO: 61388963).

\section{Conflicts of interest}

There are no conflicts to declare. 


\section{Notes and references}

¥ The matrix notation of this structure is $(50,28)$. The $(2 \times 2)$ transformation matrix, linking the adsorbate lattice vectors (b1, b2) to the substrate lattice vectors $(a 1, a 2)$ via b1 $=m^{11} a 1+m^{12} a 2$ and $b 2=m^{21} a 1+m^{22} a 2$, is written here in the form $\left(m^{11} m^{12}, m^{21}\right.$ $\left.\mathrm{m}^{22}\right) \cdot{ }^{37}$

1 C. Viedma, G. Coquerel and P. Cintas, in Handbook of Crystal Growth, Elsevier B.V., Second Edition. 2014, pp. 951-1002.

2 L. Pasteur, Ann. Phys., 1848, 24, 442-459.

3 G. Coquerel, Enantiomer, 2000, 5, 481-498.

4 O. Wallach, Justus Liebigs Ann. Chem., 1895, 286, 119-143.

5 K.-H. Ernst, Isr. J. Chem., 2016, 57, 24-30.

6 C. P. Brock, W. B. Schweizer and J. D. Dunitz, J. Am. Chem. Soc., 1991, 113, 9811-9820.

7 J. D. Dunitz and A. Gavezzotti, J. Phys. Chem. B, 2012, 116, 6740-6750.

8 R. Raval, Chem. Soc. Rev., 2009, 38, 707-721.

9 K.-H. Ernst, Surf. Sci., 2013, 613, 1-5.

10 S. De Feyter and F. C. De Schryver, Chem. Soc. Rev., 2003, 32, 139-150.

11 Y. Yang, R. C. da Costa, M. J. Fuchter and A. J. Campbell, Nat. Photonics, 2013, 7, 634-638.

12 M. Kettner, V. V. Maslyuk, D. Nürenberg, J. Seibel, R. Gutierrez, G. Cuniberti, K.-H. Ernst and H. Zacharias, J. Phys. Chem. Lett., 2018, 9, 2025-2030.

13 V. Kiran, S. P. Mathew, S. R. Cohen, I. Hernández Delgado, J. Lacour and R. Naaman, Adv. Mater., 2016, 28, 1957-1962.

14 O. Stetsovych, P. Mutombo, M. Švec, M. Šámal, J. Nejedlý, I. Císařová, H. Vázquez, M. Moro-Lagares, J. Berger, J. Vacek, I. G. Stará, I. Starý and P. Jelínek, J. Am. Chem. Soc., 2018, 140, 940-946.

15 Y. Shen and C.-F. Chen, Chem. Rev., 2012, 112, 1463-1535.

16 M. Gingras, Chem. Soc. Rev., 2013, 42, 1051-1095.

17 K.-H. Ernst, Acc. Chem. Res., 2016, 49, 1182-1190.

18 J. Seibel, M. Parschau and K.-H. Ernst, J. Phys. Chem. C, 2014, 118, 29135-29141.

19 J. Seibel, L. Zoppi and K.-H. Ernst, Chem. Commun. (Camb.), 2014, 50, 8751-8753.

20 H. Ascolani, M. W. van der Meijden, L. J. Cristina, J. E. Gayone, R. M. Kellogg, J. D. Fuhr and M. X. Lingenfelder, Chem. Commun. (Camb.), 2014, 50, 13907-13909.
21 J. D. Fuhr, M. W. van der Meijden, L. J. Cristina, L. M. R. X. guez, R. M. Kellogg, J. E. Gayone, H. Ascolani and M. X. Lingenfelder, Chem. Commun. (Camb.), 2017, 53, 130-133.

22 J. Seibel, M. Parschau and K.-H. Ernst, J. Am. Chem. Soc., 2015, 137, 7970-7973.

23 M. Stöhr, S. Boz, M. Schär, M.-T. Nguyen, C. A. Pignedoli, D. Passerone, W. B. Schweizer, C. Thilgen, T. A. Jung and F. Diederich, Angew. Chem. Int. Ed., 2011, 50, 9982-9986.

24 A. Mairena, L. Zoppi, J. Seibel, A. F. Tröster, K. Grenader, M. Parschau, A. Terfort and K.-H. Ernst, ACS Nano, 2017, 11, 865-871.

25 J. Seibel, O. Allemann, J. S. Siegel and K.-H. Ernst, J. Am. Chem. Soc., 2013, 135, 7434-7437.

26 A. Mairena, M. Parschau, J. Seibel, M. Wienke, D. Rentsch, A. Terfort and K.-H. Ernst, Chem. Commun. (Camb.), 2018, 54, $8757-8760$

27 J. Li, K. Martin, N. Avarvari, C. Wäckerlin and K.-H. Ernst, Chem. Comm., 2018, 54, 7948-7951.

28 O. Stetsovych, M. Švec, J. Vacek, J. V. Chocholoušová, A. Jancarik, J. Rybáček, K. Kosmider, I. G. Stará, P. Jelínek and I. Starý, Nat. Chem., 2017, 9, 213-218.

29 M. Parschau, R. Fasel and K.-H. Ernst, Cryst. Growth Des., 2008, 8, 1890-1896.

30 R. Fasel, M. Parschau and K.-H. Ernst, Angew. Chem. Int. Ed., 2003, 42, 5178-5181.

31 L. Dong, P. N. Liu and N. Lin, Acc. Chem. Res., 2015, 48, 27652774

32 S. A. Suarez, F. Müller, M. E. Gutierrez Suburu, A. Fonrouge, R. F. Baggio and F. D. Cukiernik, Acta Cryst. 2016, B72, 693701.

33 H. F. Lieberman, R. J. Davey and D. M. T. Newsham, Chem. Mater., 2000, 12, 490-494.

34 K.-H. Ernst, S. Baumann, C. P. Lutz, J. Seibel, L. Zoppi and A. J. Heinrich, Nano Lett., 2015, 15, 5388-5392.

35 K. Toyoda, Y. Nakano, I. Hamada, K. Lee, S. Yanagisawa and Y. Morikawa, J. Electron Spectrosc. Relat. Phenom., 2009, 174, 78-84.

36 J. A. Smerdon, M. Bode, N. P. Guisinger and J. R. Guest, Phys. Rev. B, 2011, 84, 165436-1-7.

37 L. Merz and K.-H. Ernst, Surf. Sci., 2010, 604, 1049-1054. 